\title{
¿Traducción, adaptación o versión?: maremágnum terminológico en el ámbito de la traducción dramática
}

\author{
JORGE BRAGA RIERA \\ Universidad Complutense de Madrid \\ jbragariera@filol.ucm.es
}

Recibido: 29 de mayo de 2010

Aceptado: 10 de noviembre de 2010

\section{RESUMEN}

La doble naturaleza del texto dramático, que se erige en texto literario y guión teatral para su puesta en escena, hace que, elementos lingüísticos aparte, entren en juego factores no verbales con un peso específico en el proceso traductor. Esta singularidad ha propiciado el empleo de términos tales como "traducción", "adaptación" o "versión" para referirse precisamente al particular trasvase lingüístico, cultural y escénico que supone la traducción de obras de teatro. Sin ánimo de plantear dónde debe trazarse la frontera de lo que constituye o no "traducción", este artículo pretende dejar constancia de la utilización de estos y otros conceptos semejantes en el ámbito dramático, así como plantear el debate sobre la necesidad de unificar criterios terminológicos dentro de los llamados Estudios de Traducción Teatral.

Palabras clave: Estudios de traducción, traducción dramática, adaptación, versión.

Translation, adaptation, or version?: Plethora of terms within the area of drama translation

\begin{abstract}
The double nature of the play text as both a literary text and a play script whose ultimate aim is its mise en scène conveys a series of linguistic and extralinguistic factors that have a say in the translation process. This singularity has brought about the use of different terms -"translation", "adaptation", "version"- precisely to refer to the particular linguistic, cultural and stage rendering that is inherent to play translation. Far from trying to fix the limits of what "translation" should be in theatre, this article aims to show the use of these and other similar concepts in the field in an attempt to invite discussion about the need to standardize terminological criteria within the so-called Drama Translation Studies.
\end{abstract}

Key words: Translation Studies, drama translation, adaptation, version. 
Sumario: 1. Introducción. 2. Sobre la naturaleza de la traducción dramática. 3. Traducción, versión y otras etiquetas: la figura del "traductor". 4. Conclusiones.

\section{Introducción}

Hace ya más de diez años, concretamente el 14 de febrero de 1998, La vida es sueño cruzaba el Atlántico y se estrenaba en Hartford (Connecticut) con el título de Sueño: A Play in Three Acts ${ }^{1}$. Su traductor al inglés en esta ocasión, el portorriqueño José Rivera, pretendía, a partir del texto calderoniano, "ser fiel a la historia original casi paso a paso, con solo un par de cambios estructurales, y alguna reimaginación al final de la obra" (en Castilla 2003: 198). Este "par de cambios", sin embargo, acarreaba la eliminación de partes del original y una constante vulgarización del lenguaje; es más, también la trama se veía afectada: así el emplazamiento de la acción (que ya no trascurría en Polonia, sino en la España de 1635) y la escena final donde, al más puro estilo Hollywood, Segismundo se esposa con Rosaura, quienes, convencidos de que la vida ya "no es un sueño", deciden embarcarse al Nuevo Mundo. Con todo, y pese a las modificaciones realizadas, Rivera dejaba claro que su obra es "una traducción y una adaptación".

Ya en nuestro país, y más de una década después, la cartelera madrileña incluía en su programación El enfermo imaginario, de Moliere. La publicidad del evento calificaba el texto español de "nueva versión modernizada"3, si bien su "creador", Gabriel Olivares, apostillaba que se trataba de una "adaptación muy libre"4. Idéntica apreciación fue la recibida por Laura $C$, traducción española de Waiting for $G o d o t^{5}$. En esta ocasión, no obstante, se hacía un doble distingo: por un lado, la participación de los "adaptadores libres" (Francesco Beltrán y Pasquale Marino); por otro, la presencia de Javier Navarro Climent, encargado de "traducir" el original de Beckett a la lengua española. También en Madrid y por estas mismas fechas, Ainhoa Amestoy presentaba su montaje Mucho ruido y pocas nueces, una "versión" (en palabras de El País) de la comedia de Shakespeare ${ }^{6}$. Finalmente, la domesticada Piedras en los bolsillos, de la irlandesa Marie Jones, aparecía recientemente publicitada como versión y adaptación ${ }^{7}$.

1 http://www.hartfordstage.org. Las representaciones continuaron hasta el 21 de marzo de ese mismo año. Véanse los estudios de Castilla (2003) y Quintero (2009) sobre este montaje.

2 http://www.dramaticpublishing.com/p1468/Sueno/product_info.html.

3 El teatro Fígaro-Adolfo Marsillach fue el espacio elegido para acoger esta pieza, que permaneció en cartel durante los primeros meses de 2010: http://madrid.kedin.es/event/24113/el-enfermo-imaginario-en-elteatro-figaro-adolfo-marsillach.

4 http://www.lukor.com/not-esp/terrorismo/0902/06084818.htm.

5 La compañía Residui Teatro fue la encargada de montar la obra, que pudo verse en el Teatro Arenal (Madrid) en abril de 2010: http://www.residuiteatro.com/todas-las-producciones/45-laurac.html.

6 http://www.elpais.com/articulo/madrid/Amestoy/nueva/saga/teatral/elpepiespmad/20100418elp$\operatorname{mad} 12 /$ Tes.

$\overline{7}$ Teatro Lara de Madrid, enero-marzo de 2010. La adaptación al español de la pieza original, Stones in his Pockets, corrió a cargo de Juan Cavestany. 
A la vista de la terminología utilizada en todos estos ejemplos, resulta complicado, cuanto menos, hacer distinciones entre lo que podríamos entender a priori por traducción, versión, adaptación, o, incluso, adaptación libre, dada la vaguedad de los conceptos en cuestión, cuyo significado varía, además, según quién los utilice. Pues bien, esta tarea se torna aún más compleja si trasplantamos estos mismos términos a otros medios más allá del estrictamente teatral. Así, y hace ya unos años, el diario El País aludía al Hamlet catalán realizado para la televisión por Terenci Moix del siguiente modo: "Hamlet, de Shakespeare, según la versión y traducción al catalán de Terenci Moix. Esta importante adaptación del escritor catalán se emitió en su versión original por el circuito catalano-balear"8. A tenor de las voces utilizadas, el proceso de conversión de una pieza de una lengua (la inglesa) a otra (el catalán), en este caso para otro medio (la televisión), quedaba abierto a la interpretación semántica.

Sirvan estas primeras líneas a modo bosquejo sobre una realidad inherente a la traducción teatral que no solo afecta a la escena contemporánea, sino que siempre ha estado presente en el trascurso de la historia de la dramaturgia. Ahora bien, es cierto que, en nuestros días, y en calidad de espectadores de teatro, cada vez nos estamos familiarizando más con los términos de "adaptación" y "versión", que parecen haber sustituido en los carteles y programas de mano a la palabra "traducción". El conflicto estriba en que esta diferente terminología se usa, como se ha visto, sin rigor alguno la mayoría de las veces, lo cual complica cualquier intento de establecer diferencias lo suficientemente nítidas. Más confusa resulta aún dicha labor cuando, al tratar de averiguar el alcance real de estos vocablos, nos encontramos en la variada literatura con otros tales como "recreación", "reescritura", "recomposición", "transliteración", "refundición", creative rewrite, creative translation, remake, refraction, interpretation, relocation ${ }^{9}$, transposition ${ }^{10}$, transplantation, tradaptation ${ }^{11}$, "adaptación libre" e, incluso, "retraducción"12", por no mencionar los peyorativos "manipulación", "plagio", "crimen"13, collage o "traición"14.

${ }^{8}$ El Pais, 8-1-1982: http://www.elpais.com/articulo/radio/television/MOIX/ TERENCI/ESPAnA/TE LEVISIoN_ESPAnOLA_/RTVE/Hamlet/version/Terenci/Moix/elpepirtv/19820108-elpepirtv_2/Tes/.

${ }^{9} \mathrm{O}$ único proceso, según el traductor Ben Gunter (2008), para reproducir una pieza teatral en otro lugar y tiempo.

${ }_{10}$ Vocablo este propuesto por Zuber-Skerritt (1984: 8) como sinónimo de traducción para la escena.

11 "Término empleado por directores y estudiosos que trabajan desde un discurso postcolonial o intercultural $[\ldots]$ para aludir a una nueva reescritura del texto realizada con una perspectiva no occidental" (Perteghella 2004: 18; mi traducción).

${ }_{12}$ Para una información más extensa sobre el alcance de la retraducción, véase Zaro 2007.

13 Santoyo (1989b: 75) tilda de "crímenes" prácticas tales como una mala versión lingüística, la ausencia de riqueza verbal, la eliminación de líneas o el desplazamiento de diálogos (todas ellas, dicho sea de paso, bastante habituales en la práctica traductora pensada para las tablas).

${ }_{14}$ Algunas de estas palabras se emplean también para referirse al proceso de adecuación de un texto teatral destinado a producir una versión diferente en la misma lengua original. Así, Ruano de la Haza especifica diferentes técnicas de auto-reescritura (refundición, reelaboración, reconstrucción, adaptación, reutilización), mientras que Profeti habla de intertextualidad, paratextualidad, collage e interdiscursividad en el texto literario del teatro áureo (en Urzáiz 2002b: 378). Urzáiz Tortajada (2001) distingue, además, entre "reelaboración" y "autoplagio", o calco textual. Héctor Brioso (2007: 11) opta por el sustantivo "distorsión", y no adaptación, al calificar algunas de las representaciones actuales del teatro áureo en nuestro país. 
En uno de los últimos libros publicados en nuestro país -quizás el más recientededicado íntegramente a la traducción dramática (Teatro y traducción: Aproximación interdisciplinaria desde la obra de Shakespeare), su autora, Pilar Ezpeleta, tras recoger las opiniones más relevantes vertidas sobre los intríngulis de la traducción teatral, detalla algunas de las preocupaciones actuales en este campo. Entre ellas, apunta tanto "la necesidad de delimitar y definir claramente qué entendemos por teatro y drama" como la querencia por "perfilar adecuadamente el papel y la responsabilidad del traductor, tanto respecto del texto dramático de partida como del texto meta" (2007: 159-160). El presente artículo se enmarca, pues, en esta línea y aborda la ardua tarea de arrojar luz sobre el alcance de los términos "traducción", "adaptación" y versión" en el ámbito dramático, recurriendo para ello al análisis de las opiniones vertidas por algunos estudiosos en la materia. Con todo, no se pretende aquí ofrecer pautas prescriptivas al respecto, sino dejar constancia del -nada baladí- caos terminológico que rodea la denominación de las traducciones pensadas para la escena.

\section{Sobre la naturaleza de la traducción dramática}

A theatre performance is transitory and is subject to changes according to audience reaction, acting performance, physical environment, etc. Whereas the translated and published drama text remains irrevocable and permanent, each theatre performance based on this text is different and unique. Yet, [...] drama translation must be concerned both with the translated text (as the basis for the stage production) and the individual theatrical performances. (Zuber-Skerritt 1984: 9)

Estas palabras de Zuber-Skerritt, pionera de los llamados Drama Translation Studies, venían a definir claramente, allá por los años ochenta, la singularidad de la pieza teatral y la importancia que adquieren tanto el texto como la representación en la actividad traductora. Y es que, aparte de los sempiternos factores lingüísticos, no podamos pasar por alto todos aquellos componentes no verbales condicionantes de la traducción de los textos teatrales, tales como la cultura ${ }^{15}$, la figura del traductor, el gesto, el escenario, la luz y el sonido, los decorados, la música y el vestuario, sin olvidar las restricciones de corte económico o la aceptación por parte del espectador, cuando no la censura (Braga Riera 2009). Atrás quedaba, pues, la concepción de la traducción dramática como un trabajo académico centrado exclusivamente en su dimensión textual y no pensado para ser disfrutado sobre las tablas ${ }^{16}$.

15 Entendida esta no solo como modo de vida y costumbres, sino también como "cultura dramática", en cuanto afecta a la tradición y usos teatrales del país de acogida. Curiosamente Mona Baker (1996: 145) ya alertaba, hace más de una década, del riesgo que entrañaba la palabra "cultura" en los estudios de traducción, pues en muchos casos sirve como justificación de falta de rigor y coherencia.

16 Aaltonen (2000: 4) distingue entre el teatro pensado para su posterior representación (theatre translation) y aquel que tan solo forma parte del canon literario como texto escrito (drama translation). 
No obstante, esta concepto de traducción dramática que abarca el texto tanto desde su faceta literaria como escénica (guión teatral) parece entrar en contradicción con una tendencia bastante extendida en estos tiempos, que no es otra que la de denominar exclusivamente "traducción" a lo que llamaríamos una traducción "fiel" del texto fuente, que se erigiría a su vez en eslabón inicial para una posterior "adaptación" (caso de Laura C., ya visto arriba). Este proceso, que viene siendo práctica habitual también en otros países (Bassnett 1991, Mateo 2000, 2002), arranca, pues, con una traducción "literal" previa de la pieza origen (conocida en inglés como the literals), que suele ser llevada a cabo por un traductor generalmente anónimo. A partir de aquí, es el "adaptador" quien, incluso sin tan siquiera conocer la lengua original, prepara un texto meta ${ }^{17}$. En otros casos, no queda constancia de esta diferenciación de roles, circunstancia que, claro está, propicia la diversidad terminológi$\mathrm{ca}^{18}$.

Con todo, es un hecho constatado que apenas si existen producciones que representen un texto traducido sin que este haya pasado por un proceso de adaptación que acarrea enmiendas, cortes, sustituciones o añadiduras. A este respecto no cabe sino mencionar las palabras de la ya fallecida traductora Inga-Stina Ewbank (en Fischer 2007: 35) ${ }^{19}$ y refrendadas por Barbara Mujica (2008: 241), quien afirmaba que "toda producción teatral constituye una traducción" (mi traducción), o las -más radicalesexpresadas por el traductor Ben Gunter, quien apostilla que "la fidelidad filológica adultera la dramaturgia" (2008: 123, mi traducción). Controvertidas o no, estas opiniones cobran un sentido especial en el caso, por ejemplo, de los clásicos, ya que estos, por su naturaleza, se prestan a muchas interpretaciones (Sáenz 2001: 1) ${ }^{20}$. Ya mencionamos como Rivera decidía por su cuenta y riesgo alterar el significado de la pieza de Calderón, propiciando una lectura, quién sabe si errónea, por parte de espectador estadounidense. Sobre este particular se manifestaba también el hispanista Gwynne Edwards, traductor de comedias españolas y muy crítico con las traducciones al inglés de unos de sus colegas, como el ya referido Adrian Mitchell, de

17 Un claro ejemplo es la traducción de El alcalde de Zalamea de Adrian Mitchell, montada por el National Theatre en Londres en 1981-1982, a la que se dio el título de The Mayor of Zalamea; or the Best Garrotting Ever Done. El propio Mitchell reconoce que cuando aceptó el encargo de preparar la versión inglesa no sabía casi nada de la lengua española, por lo que basó su trabajo en una traducción previa realizada por alguien que sí dominaba el idioma (Smith 1993: 129-130). Ahora bien, estas primeras traducciones, si no son muy adecuadas, pueden provocar el efecto contrario y contribuir a hacer más profundas las divergencias con el original (véase Dixon 1991 para ilustrar este aspecto). De ahí que muchos apelen a lo que Mountjoy denomina "devised translation" (en Smith 2008: 106), o colaboración estrecha entre el primer traductor y el encargado de llevar el texto al escenario, o, incluso, los actores.

18 Algunos traductores tienen en su haber, incluso, dos versiones distintas de la misma obra: una de ellas, de corte más académico, suele venir acompañada de un estudio introductorio y notas, mientras que la otra está pensada exclusivamente para la representación. Sirva de ejemplo el estadounidense Dakin Matthews y sus dobles traducciones al inglés de La verdad sospechosa y Las paredes oyen, ambas originales del novohispano Juan Ruiz de Alarcón.

${ }^{19}$ Ewbank ha traducido a Ibsen y a Strindberg, entre otros autores.

20 Sáenz señala el respeto, la confianza y la libertad como los tres principios teóricos fundamentales a la hora de traducir a los clásicos. No obstante, alerta de los peligros de "confundir libertad con libertinaje" (2001: 1). 
quien comentaba lo siguiente: "Lo más preocupante es que las versiones hechas por Mitchell son frecuentemente aclamadas por los críticos ingleses, quienes las elogian por su energía y vivacidad, y lo que es una parodia del original es aceptada por el público inglés como el trabajo de Calderón o de Lope de Vega" (1989: 37). No anda errado Edwards si a esto añadimos lo pintoresco de muchas de las puestas en escena de nuestros autores áureos en el mundo anglosajón hoy día. En Sueño..., el tono hispano que impregnaba la representación se vio acentuado aún más por la presencia escénica de un guitarrista que acompañaba la acción a ritmo de flamenco, y algunos personajes -incluso- se arrancaron a bailar a golpe de castañuelas ${ }^{21}$. Phyllis Zatlin (2005: 69) da fe, precisamente, de la imagen andaluza que emana de muchas de las obras españolas que viajan a Estados Unidos, aun cuando los textos fuente vengan enmarcados por los paisajes gallegos de Ramón de Valle-Inclán o por la arquitectura madrileña de Paloma Pedrero (esta última sustituida por un póster de un cortijo para una producción neoyorquina) ${ }^{22}$. Y es que, aun cuando el proceso de traducción teatral pueda siempre verse alterado por la última palabra del director o de los actores, también es cierto, como denuncia Fischer, que "este proceso no sanciona la tergiversación del texto" (2005: 176, mi traducción). De ahí que el reputado Lawrence Boswell, en calidad de director artístico del célebre Festival de Teatro Clásico Español organizado por la Royal Shakespeare Company en 2004, dejara claro que, en un deseo de no infravalorar al público, todos los textos elegidos para ese festival serían "traducciones exactas, no adaptaciones" (en Mountjoy 2007: 75, mi traducción $)^{23}$. Pese a estas declaraciones, los textos acabaron sufrieron cambios sustanciales antes del estreno.

¿Cómo esclarecer, por tanto, qué está permitido, y qué no, en el trasvase de un texto dramático de una lengua y cultura determinadas a otras completamente diferentes para que el producto se considere traducción? ¿Acaso debemos utilizar diversas etiquetas dependiendo del grado de fidelidad o "lealtad" (Nord 2002) con respecto del texto origen? Y de ser así, ¿qué entendemos por estos dos conceptos? La lengua inglesa lo tiene igual de complicado en este sentido, pues, como bien ha observado Bassnett (1998: 94-95), la palabra translation alude en ciertas ocasiones

\footnotetext{
${ }^{21} \mathrm{http}: / / \mathrm{www} . c u r t a i n u p . c o m / s u e n o . h t m l$. No en vano el flamenco sigue siendo el punto de contacto más prominente con lo español. Podemos citar a este respecto la producción de El perro del hortelano de la Royal Shakespeare Company (2004), que contaba con un experto en flamenco entre el equipo técnico (Delgado 2007: 121), o el montaje de Friendship Betrayed (La traición de la amistad, de María de Zayas) en Hollywood (1996), donde flamenco y guitarra española alternaban con canciones country (Mujica 2008: 252).

${ }_{22}$ La obra en cuestión era Parting Gestures, representada en la Universidad de Pace en 1991. También los rasgos fonológicos de la lengua de llegada pueden provocar alteraciones, por ejemplo en el nombre de los personajes: en su traducción al inglés de Hay que deshacer la casa (Packing Up the Past), Ana Mengual optó porque uno de los personajes, Jorge, pasara a llamarse Carlos, pues la pronunciación del nombre original en esa lengua (hor-hay) podía producir un efecto cómico poco pertinente. Otro tanto hizo Zatlin (2005: 73-74) al sustituir Jaimito por Pepito en su versión al inglés de Bajarse al moro, dadas las connotaciones judías derivadas de la fonética del primero (ibid: 74).

${ }^{23}$ Esta temporada consiguió la puesta en escena por toda Inglaterra de nuevas traducciones de El perro del hortelano, Pedro de Urdemalas, La venganza de Tamar y Los empeños de una casa. El público madrileño tuvo también la oportunidad de disfrutar de las representaciones (esta vez con sobretítulos en castellano), concretamente en el Teatro Español de Madrid dentro de la programación del Festival de Otoño de 2004.
} 
al trasvase de un texto origen a la cultura de llegada, mientras que en otras implica la transposición de un texto escrito a las tablas, esto es, la llamada mise en scène; de ahí que la etiqueta de "traducción" pueda aplicarse en estos casos, y no únicamente en lo que se conoce como "traducción literal". Pues bien, ya en nuestro país, y al objeto de acotar la dimensión que alcanza el término "traducción” en dramaturgia, veamos en qué consisten realmente los procesos -así llamados por algunos- de "adaptación" y de "versión".

\section{Adaptación, versión y otras etiquetas: la figura del "traductor"}

Acabamos de ver cómo la traducción teatral conlleva toda una serie de exigencias que no se dan en otro tipo de textos literarios, por lo que el traductor, a veces, toma decisiones susceptibles de ser criticadas por su "infidelidad" con respecto del original. Como consecuencia, prefiere en ocasiones utilizar los términos de "versión" o "adaptación” para, así, salir al paso de los ataques más ortodoxos sin que ello suponga avergonzarse de su producto (Dixon 1991: 95), o bien lo hace porque estos términos serían "mejor vistos" en el mundo del teatro, acostumbrado como está este a equiparar "traducción" con un texto poco natural no apto para ponerlo en boca de los actores (Mateo 2002: 55-56). Otras veces, la elección de la nomenclatura viene condicionada por razones de taquilla, cuando el "adaptador" es alguien conocido dentro del mundo de las letras, el espectáculo o los medios de comunicación, caso en el contexto español de Josep María Flotats o el propio Moix, entre otros; se produce, así, un proceso de "apropiación" en el que autor de la pieza original puede llegar a desaparecer (Mateo 2002) ${ }^{24}$. No obstante, y pese a que la denominación de "traducción" pudiera implicar una mayor cercanía al original, hay ocasiones en las que, aun alterándose formas y estilos, los textos meta aparecen igualmente descritos como "traducciones". Del mismo modo, se tildan de "traductores" personas relevantes dentro de la dramaturgia que llegan a poner su nombre a obras sin ni tan siquiera conocer el idioma del texto del que parten ${ }^{25}$.

El crítico y autor Enrique Llovet entiende por “adaptación” (o "versión”, que utiliza con el mismo significado) un proceso de reescritura del original que acomete

ciertas transformaciones de fondo y forma en una obra determinada, normalmente con el propósito de hacerla inteligible -si procede de otro género-, aceptable -si una presión cualquiera entorpece la representación integral- o, sencillamente,

24 Merino (2001: 362) menciona el caso de la pieza estadounidense Mulatto, de Langston Hughes, dada a conocer en nuestro país en 1967 gracias a la fama de su traductor al español, el polémico Alfonso Sastre.

25 Aaltonen (2000: 32) utiliza en estos casos el término surrogate translators, esto es, "traductores sustitutos" que, normalmente, crean una versión escénica a partir de una traducción literal realizada por una persona anónima. Esta práctica, que responde generalmente a intereses comerciales, es muy habitual en algunos países en la actualidad, como Gran Bretaña, si bien cuenta con el rechazo de otras culturas teatrales (Mateo 2002: 52). 
mejorada y ajustada a los conceptos y a las normas sociales de un país, una época y una audiencia específicas.

(Llovet 1988: 3)

Llovet defiende este tipo de operación por ser necesaria en muchas ocasiones, debido a factores como la censura, dificultades económicas, problemas de reparto, así como los escollos lingüísticos generales y específicos, y los sociológicos, esto es, los que relacionan el texto con una época y una población teatral determinadas. Se trata, por tanto, de una operación intermedia entre el hecho literario y el escénico.

Esta noción de adaptación concebida como una adecuada reescritura del drama, que alcanza así en la nueva audiencia los objetivos efectivos que el original persigue, coincide en ciertos aspectos con la noción que Lefevere tiene de refraction, y que el estudioso belga detalla así:

It denotes the rewriting of texts [...] in order to make them acceptable for a new audience. In the process virtually every feature of the original may be changed, or else very little may be changed. Changes will usually fall under three categories: a change of the language in which the original is written, with its concomitant socio-cultural context, a change of the ideology of the original (i.e., its 'world view' in the widest, not just the political sense of the world) and a change of the poetics of the original (i.e., the presuppositions as to what it is, or is not, literature) that can be seen to have guided the author of the original, whether he/she follows them or rebels against them. (en Zuber-Skerritt 1984: 192)

No obstante, el término refraction es mucho más amplio que el expresado por Llovet, pues con él se pretende abarcar tanto la traducción como la producción de piezas teatrales.

Santoyo, a diferencia de Llovet, sí distingue entre "versión" y "adaptación”, pues considera que la primera es "dar nueva disposición a una obra de ingenio para modernizarla" (Santoyo 1989a: 100), pero con miras escénicas. Por otro lado, el concepto que el autor leonés tiene del término "adaptación" es más general, ya que afirma que bajo esta etiqueta cabe todo:

Naturalizar teatro en una nueva cultura meta [...]; acomodar, adecuar y ajustar particulares a las expectativas de un colectivo distinto, separado del primero por un amplio gap sociocultural de tiempo o espacio, o de ambos a la vez. El adaptador salva este distanciamiento y reduce el handicap previsible de recepción en la audiencia meta [...] Adaptación, pues, pero a un nuevo código cultural: nunca rifacimento. Cuanto se haga al otro lado de esta frontera transgrede por fuerza los derechos del autor y de los espectadores, y (lo que es peor) traiciona radicalmente la idiosincrasia del original. Cuanto se haga más allá de esta demarcación ha de reconocerse como tal y responde mejor a consideraciones posteriores sobre la reescritura o adaptación libre. (Santoyo 1989a: 104)

Santoyo introduce, pues, un nuevo término, el de la "adaptación libre", que considera sinónimo de "reescritura", o, siguiendo la terminología cinematográfica 
moderna, un remake. El adaptador "se desvincula del texto, forma y parámetros culturales para, sin soltar del todo las amarras que lo unen a él, proceder a tales modificaciones que bajo muchos aspectos el producto resultante no equivale ya a aquel del que deriva" (1989b: 195).

También Manuel Ángel Conejero opta por "reescritura" o rewriting (si bien en un sentido más positivo que el otorgado por Santoyo) cuando "we are referring to the translation not of words, but of styles and the world of sounds, and this is how theatre can truly be translated, written into another language" (1991: 57). El mismo término, rewriting, es igualmente empleado por Lefevere (1992: 14-15) para definir un proceso en virtud del cual "texts are manipulated to suit the constraints that the system imposes on foreign objects which enter it". Estas constraints, o "restricciones", vienen impuestas fundamentalmente por dos facciones distintas: la primera, la formada por estudiosos, traductores, editores, etc., más pendientes de la "estética" del texto extranjero; la segunda viene marcada por lo que Lefevere denomina patronage ("mecenazgo, patrocinio"), esto es, quién decide qué y cómo se traduce en virtud de la ideología preponderante o de unos intereses comerciales determinados.

El problema estriba en definir la estrecha frontera que media entre la mera adaptación y la llamada adaptación libre. De nuevo, Llovet hace una división tripartita de tipos de adaptaciones, una de las cuales califica, precisamente, de "libre"26. Bajo esta denominación se enmarcan aquellas traducciones en las que se usa "el texto original como un sencillo pretexto para decir lo que viene en gana al director y al adaptador" (1988: 9). Pero muchas veces el traductor va más allá y lleva a cabo remakes que pudieran carecer de toda justificación; añade, trastoca y modifica sin ningún tipo de rigor, aprovechándose incluso -como hemos visto- de la labor de un autor extranjero asumiéndola como propia: en estos casos, podríamos ya estar hablando de "plagio".

El traductor teatral Gitlitz expresa su repulsa total al plagio, pues "no responde a método ni a proceso alguno de transferencia intertextual, semiológica o interlingüística. No obstante, el plagiario hace uso del resultado de tales procesos en beneficio propio y con más frecuencia de lo deseable [...], ampara su vocación de fotocopia bajo apelativos más nobles como el traductor, adaptador, etc." (1989: 108). A su vez, Gitlitz distingue entre el plagio propiamente dicho, es decir, "la reproducción parcial o total, bajo nueva firma, de traducciones y adaptaciones dramáticas previas" y lo que él denomina "recomposición", que no es más que un "plagio múltiple de quien, incapaz de traducir, fagocita en provecho propio fragmentos de versiones ajenas para construir con ellos su propia versión/traducción, que evidentemente no es suya, ni propia, ni responde siquiera a un proceso traductor" (ibid.: 109) ${ }^{27}$.

Plagios aparte, resulta necesario concretar cuándo un texto traducido en el sentido general de la palabra responde a la concepción de adaptación o adaptación libre,

${ }^{26}$ Las otras dos serían las llamadas "limpiadora" y "moderna".

${ }^{27}$ Mateo (2002: 54) apunta incluso casos de denuncias por parte de traductores que han visto cómo su trabajo era plagiado por conocidos escritores para, posteriormente, ser montado en importantes compañías teatrales españolas, sin que en ningún momento constara quién es el autor de esa traducción. 
dependiendo de las estrategias utilizadas. Merino (1994: 25-26) concibe la adaptación como un proceso de adecuación lingüística y cultural -no exclusivo de la literatura dramática- a un determinado país o época, aunque no la considera un tipo de traducción, sino más bien parte de ese proceso. Reserva, pues, el término "versión", al igual que Santoyo, al texto escrito que se destina a un medio determinado, principalmente a la escena. Aaltonen (2000: 64), sin embargo, entiende la adaptación como la traducción teatral que hace un uso parcial del texto original, mientras que utiliza el término "imitación" para aquellas piezas que se inspiran en temas o ideas de obras extranjeras:

An adaptation may thus reactualise the foreign source by translating only parts of it, while other parts vanish or are changed. It may reactualise the foreign source text spatially and/or temporally, but in all these cases the adaptation still claims to represent the source text in the target system. Finally, and as subcategory of adaptation, an imitation borrows an idea or theme from the foreign source text and writes a new play around it. (Aaltonen 2000: 64)

Por otro lado, y del mismo modo que el traspase de un texto teatral de una lengua a otra es descrito de las más diversas formas, la persona encargada de llevarlo a efecto adquiere, como no podía ser de otra manera, multitud de calificativos en el contexto dramático: "traductor", "adaptador", "versionista", e, incluso "creador escénico". El dramaturgo Domingo Miras diferencia, curiosamente, entre adaptador y versionista, pues, según él, este último "quiere manifestarse; el adaptador, no" (en Oliva 1995: 429). Un estudio realizado por Jänis (1996: 352) añade a la lista interpreter ("intérprete"), deputy ("suplente"), servant ("sirviente") y surrogate ("sustituto"). Finalmente, Aaltonen (1996: 90) recurre a los vocablos mediator y creator para referirse al traductor teatral. No obstante, establece una diferencia entre ellos: aquellos traductores cuya única relación con la obra se basa en el mismo texto, y carecen de poder fuera de éste, entrarían más en la categoría de mediators; aquellos cuyo poder de trabajo llega hasta el escenario, bien por ser escenógrafos, directores de escena, bien por trabajar en íntima relación con ellos, estarían más cerca del concepto de creator, ya que pueden realizar ajustes a su antojo y deducir diversas interpretaciones de acuerdo con las necesidades del momento. Nos encontramos, en fin, ante multitud de posibilidades para designar una figura que, en palabras de Dixon (1991: 110), debería aunar, nada más y nada menos, la condición de historiador, crítico, lingüista, poeta, director y actor.

\section{Conclusiones}

A lo largo de estas páginas hemos proporcionado una serie de testimonios a cargo de teóricos, dramaturgos y traductores teatrales que han dejado constancia de su particular visión de la traducción para la escena. Teniendo en cuenta el caos terminológico reinante, resulta difícil decantarse por una u otra concepción de este trasvase, y mucho más decidir si los traductores responden a una imagen de "sir- 
vientes" (o "mediadores") ante la obra original o, por el contrario, encajan mejor en su condición de "creadores". Igualmente complejo supone hacer clasificaciones a partir de las categorías de "traducción", "versión" o "adaptación", dada la falta de claras líneas divisorias entre las tres y las diferencias expresadas por los diversos estudiosos para referirse a ellas.

Llovet, al hablar de las traducciones alemanas a nuestra lengua, afirma que "convertir un texto nacido en alemán, para espectadores alemanes, en un texto para españoles no es traducir. Tendrá que ser adaptar, buscando una y otra vez equivalencias, ritmos, modos, formas, compensaciones que se instalen en una audiencia para la que no nacieron, buscando obtener efectos similares a los producidos por el original" (1988: 12). Pero esta distinción entre "adaptar" y "traducir" parece contraponerse con el concepto cultural y funcional que se tiene de la traducción dramática en la actualidad (noción que arranca en la década de los ochenta de la mano de la ya mentada Zuber-Skerritt), puesto que, independientemente del término elegido para designar aquellas traducciones que aplican adiciones, omisiones y cambios con respecto de la obra fuente, la pieza resultante no dejará de ser, en principio, una traducción, pues se trata de un texto meta que bebe de una obra teatral origen. La única diferencia, en suma, atiende al enfoque o estrategia utilizada en cada caso.

De cualquier modo, y como parece haber quedado en evidencia, todo este desglose de conceptos no deja de ser una cuestión de nomenclatura marcada por lo que cada cual entiende por uno u otro término. De hecho, la mayoría de anuncios publicitarios, folletos, carteles, programas, críticas y comentarios sobre representaciones de textos teatrales traducidos aluden a ellas indistintamente como "traducciones", "versiones" o "adaptaciones", cuando no con otras palabras, dando una impresión de ficticia unanimidad en su interpretación. Una diferenciación nítida resultaría, qué duda cabe, extremadamente útil para el investigador. Ahora bien, una definición muy restringida del concepto de "traducción" en el campo teatral podría dejar de considerar como traducciones textos que, en su día, funcionaron como tales dentro de un tiempo y un contexto sociohistórico determinados, con independencia de su mayor o menor fidelidad a la estructura, contenidos o diálogos originales. Esta concepción funcionalista de la traducción para la escena, en cuanto que otorga un peso específico a la cultura receptora, entronca directamente con el concepto de traducción literaria desbrozado por Gideon Toury, uno de los artífices de los llamados Estudios Descriptivos de Traducción, y que bien podríamos extrapolar al caso que aquí nos concierne: "Una traducción (literaria) es aquella considerada como traducción (literaria) por una comunidad cultural concreta en una época determinada" (en Hermans 1985: 13, mi traducción).

\section{Referencias bibliográficas}

s.n., «Hamlet, según la versión de Terenci Moix», en El País, 8-1-1982.

Aaltonen, S., Acculturation of the Other: Irish Milieux in Finnish Drama Translation. Joensuu: Joensuu University Press 1996.

_, Time-sharing on Stage. Clevedon: Multilingual Matters 2000. 
Baker, M., «Linguistics and Cultural Studies: Complementary or Competing Paradigms in Translation Studies», en: Lauer, A. et. al. (eds.), Übersetzungswissenschaft im Umbruch. Tübingen: Gunter Narr 1996, 9-19.

Bassnett-McGuire, S., «Translating for the Theatre: The Case Against Performability», Traduction, Terminologie, Rédaction. Studies in the Text and its Transformations 4, 1 (1991), 99-111.

Bassnett-McGuire, S. y Lefevere, A. (eds.), Constructing Cultures. Essays on Literary Translation. Clevedon: Multilingual Matters 1998.

Braga Riera, J., La traducción al inglés de las comedias del Siglo de Oro. Madrid: Fundamentos 2009.

Brioso Santos, H., «Del arte nuevo de deshacer comedias en este tiempo o la adaptación del teatro clásico a la escena actual», en: Brioso, H. y J. V. Saval (eds.), Nuevas aportaciones a los estudios teatrales (del Siglo de Oro a nuestros días). Alcalá: Universidad 2007, 11-24.

Castilla, A., «Noticia del teatro del Siglo de Oro en Estados Unidos», en: Navarro, O. y A. Serrano (eds.), En torno al teatro del Siglo de Oro (Jornadas XVI-XVII). Almería: Instituto de Estudios Almerienses 2003, 195-201.

Conejero, M. A., Rhetoric, Theatre and Translation. Valencia: Fundación Shakespeare de España 1991.

Delgado, M. M., «Estrategias de promoción y presencia del teatro español en Gran Bretaña», en: Brioso, H. y J. V. Saval (eds.), Nuevas aportaciones a los estudios teatrales (del Siglo de Oro a nuestros días). Alcalá: Universidad 2007, 121-132.

Dixon, V., «Translating Spanish Plays for Performance: Toward a Model Approach», en: Fothergill-Payne, L. y P. (eds.), Prologue to Performance: Spanish Classical Theater Today. Londres y Toronto: Associated University Presses 1991, 93-112.

Edwards, G., «La traducción de textos dramáticos españoles al inglés», Cuadernos de teatro clásico 4 (1989), 27-43.

Ezpeleta Piorno, P., Teatro y traducción. Aproximación interdisciplinaria desde la obra de Shakespeare. Madrid: Cátedra 2007.

Fischer, S. L., «Staging Lope de Vega’s Peribáñez: The Problem of an Ending», Bulletin of Spanish Studies 82, 2 (2005), 157-179.

—, «Aspectuality, Performativity and 'Foreign' Comedia: (Re)iteration of meaning for the stage», en Boyle, C. y D. Johnston (eds.), The Spanish Golden Age in English. Londres: Oberon Books 2007, 31-48.

Gitlitz, D., «Confesiones de un traductor», Cuadernos de Teatro Clásico 4 (1989), 45-52.

Gunter, B., «Translation as Relocation», en Paun de García, S. y D. R. Larson (eds.), The Comedia in English. Translation and Performance. Woodbridge: Tamesis Books 2008, 108-124.

Hermans, T., «Translation Studies and a New Paradigm», en: Hermans, T. (ed.), The Manipulation of Literature. Studies in Literary Translation. Londres y Sydney: Croom Helm Ltd. 1985, 78-15.

Jänis, M., «What Translators of Plays Think About Their Work», Target 8, 2 (1996), 341364.

Lefevere, A., Translation, Rewriting and the Manipulation of the Literary Fame. Londres y Nueva York: Routledge 1992.

Llovet, E., «Adaptaciones teatrales», Boletín informativo de la Fundación Juan March 180 (1998), 3-16. 
Mateo, M., «La 'representabilidad' como eje de las discusiones sobre la traducción teatral», conferencia plenaria presentada en las IV Jornades de traducció a Vic: traducció teatral, Universidad de Vic, 6 de abril de 2000.

—, «Power Relations in Drama Translation», Current Writing 14, 2 (2002), 45-63.

Merino Álvarez, R., Traducción, tradición y manipulación: teatro inglés en España, 19501990. León: Universidad 1994.

—, «Drama Translation Strategies: English-Spanish (1950-1990)», Babel 46, 4 (2001), 357 365.

Mountjoy, K., «Literal and Performance Text», en: Boyle, C. y D. Johnston (eds.), The Spanish Golden Age in English. Londres: Oberon Books 2007, 75-99.

Mujica, B., «María de Zayas’s Friendship Betrayed à la Hollywood: Translation, Transculturation, and Production», en Paun de García, S. y D. R. Larson (eds.), The Comedia in English. Translation and Performance. Woodbridge: Tamesis Books 2008, 240-253.

Nord, C., «Manipulation and Loyalty in Functional Translation», Current Writing 14, 2 (2002), 32-44.

Oliva, C., «Adaptar a los clásicos, he ahí la cuestión», en: Canavaggio, J. (ed.), La comedia. Madrid: Colección de la Casa de Velázquez 1995, 425-434.

Perteghella, M., «A Descriptive-Anthropological Model of Theatre Translation», en: Klein, H. y S. Coelsch-Foisner (eds.), Drama Translation and Theatre Practice. Berna: Peter Lang 2004, 3-23.

Quintero, M. C., «Dreaming a Post-Colonial Calderón: José Rivera’s Sueño», Bulletin of the Comediantes 61, 1 (2009), 129-142.

Sáenz, M., «Respeto, confianza y libertad (II)», El trujamán, 21 de septiembre de 2001.

Santoyo, J. C., «Traducciones y adaptaciones teatrales: ensayo de tipología», Cuadernos de Teatro Clásico 4 (1989a), 95-112.

—, El delito de traducir. León: Universidad 1989b.

Smith, D. L., «Calderón en Madrid y Londres», en: Stoll, A. K. (ed.), Vidas paralelas. El teatro español y el teatro isabelino: 1580-1680. Madrid y Londres: Tamesis Books 1993, 125-135.

-, «Transformation and Fluidity in the Translation of Classical Texts for Performance: The Case of Cervantes's Entremeses», en: Paun de García, S. y D. R. Larson (eds.), The Comedia in English. Translation and Performance. Woodbridge: Tamesis Books 2008, 95-107.

Torres, R., «Los Amestoy: una nueva saga teatral», en: El País.com (29-IV-2010), http://www.elpais.com/articulo/madrid/Amestoy/nueva/saga/teatral/elpepiespmad/20100418elpmad_12/Tes.

Urzáiz Tortajada, H., «Las técnicas de reescritura en el auto La orden de Melquisedech: ¿autoplagio o reelaboración?», en: Calderón: sistema dramático y técnicas escénicas. Actas de las XXIII Jornadas de Teatro Clásico. Almagro: Universidad de Castilla La Mancha 2001, 335-362.

—, «Más sobre reescritura teatral: El golfo de las sirenas, de Calderón ¿y Funes?», en: Arellano, I. (ed.), Calderón 2000. Actas del Congreso Internacional IV Centenario del nacimiento de Calderón. Kassel: Reichenberger 2002, 369-382.

Zaro, J. J., «En torno al concepto de retraducción», en: Zaro Vera, J. J. y F. Ruiz Noguera (eds.), Retraducir: una nueva mirada. Málaga: Miguel Gómez Ediciones 2007, 21-34.

Zatlin, P., Theatrical Translation and Film Adaptation. Clevedon: Multilingual Matters 2005.

Zuber-Skerritt, O. (ed.), Page to Stage. Theatre as Translation. Ámsterdam y Atlanta: Rodopi 1984. 
Páginas web (por orden de mención)

http://www.hartfordstage.org.

http://www.dramaticpublishing.com/p1468/Sueno/product_info.html.

http://madrid.kedin.es/event/24113/el-enfermo-imaginario-en-el-teatro-figaro-adolfomarsillach.

http://www.lukor.com/not-esp/terrorismo/0902/06084818.htm.

http://www.residuiteatro.com/todas-las-producciones/45-laurac.html.

http://www.elpais.com/articulo/madrid/Amestoy/nueva/saga/teatral/elpepies$\mathrm{pmad} / 20100418 \mathrm{elpmad} 12 /$ Tes.

http://www.elpais.com/articulo/radio/television/MOIX/_TERENCI/ESPAnA/TELEVISIoN_ESPAnOLA_/RTVE/Hamlet/version/Terenci/Moix/elpepirtv/19820108elpepirtv_ $\overline{2} /$ Tes/

http://www.curtainup.com/sueno.html 